\title{
Teaching persuasiveness in legal English
}

\section{Nadežda Stojković}

\section{(2) OpenEdition}

\section{Journals}

Electronic version

URL: https://journals.openedition.org/asp/6344

DOI: $10.4000 /$ asp. 6344

ISSN: 2108-6354

\section{Publisher}

Groupe d'étude et de recherche en anglais de spécialité

\section{Printed version}

Date of publication: 1 March 2020

Number of pages: 48-62

ISSN: 1246-8185

\section{Electronic reference}

Nadežda Stojković, "Teaching persuasiveness in legal English", ASp [Online], 77 | 2020, Online since 10 March 2020, connection on 19 March 2022. URL: http://journals.openedition.org/asp/6344 ; DOI: https://doi.org/10.4000/asp.6344

This text was automatically generated on 19 March 2022.

Tous droits réservés 


\title{
Teaching persuasiveness in legal English
}

\author{
Nadežda Stojković
}

\section{Foreword}

1 This report describes an ESP teaching course in Legal English (LE) taught at the Faculty of Law at the University of Niš, Serbia, as a two-term obligatory course in a Bachelor's programme or as an elective course at Master's level. Its main objective is to empower law students with the professional linguistic skills to achieve persuasiveness and critical thinking required in a crosscultural legal context. Although the report details the different steps of the course as well as assessment procedures, it also mentions the small number of students per class (up to ten students per group), which will make it harder for teachers to develop similar courses especially in current university working conditions.

2 The methodology applied by Nadežda Stojković is both inductive and deductive, but the novelty of the author's approach lies in the will to replace classical lecturing by a discussion-based course revolving on open questions asked by Lecturer to incite students to provide clearer and more relevant answers, in accordance with the objective of helping them achieve persuasiveness in their various legal activities.

3 In the course described by N. Stojković, there are three phases of instruction that are presented in full: first of all, an introduction to the legal knowledge necessary to understand future instructions; then a presentation of basic rhetorical structures of Academic English used as examples of written rhetorical logic; finally, an identification of generic rhetorical moves and linguistic structures inherent to various legal genres such as appeal court case reports. So, N. Stojković presents the different steps followed by Lecturer to help students first formulate an informative precise title to summarize the case under consideration (for example, by getting rid of unnecessary words), then gradually produce an argumentative essay on the studied case. Another point I would like to make about the course described is that the report should have started with an earlier detailed presentation of the final taks(s) expected from the students so as to anchor the objective into real practical exercises. 
4 Two central aspects of this report are nonetheless worth mentioning. On the one hand, $N$. Stojković insists on the shift from content focus to communicative focus during classes by submitting a series of guided open questions. These questions are presented as a way to assist students to express their arguments about a case, their certainty and predictions about it, and to clarify their views and anticipate potential counter-arguments. It is true that organizing one's own persuasive arguments requires the ability to predict the possible outcomes of the case arising out of the known facts and existing case law. However, it seems that the report does not provide sufficient question models to help other teachers to implement the same methodological approach. A list of relevant progressive questions asked by Lecturer and applied to several actual cases and legal contexts would have been more beneficial to develop similar classes. On the other hand, the author makes a significant point by arguing how syntax has to work at the service of persuasion. The numerous examples of sentences provided in the last part of the report aptly demonstrate the importance of syntactic dynamics of end-focus and explain, for instance, where to place the subject to make it carry the highest persuasive charge.

5 To put it in a nutshell, I would recommend to implement the course designed by N. Stojkovic to help law students develop their legal skills of persuasiveness through a three-tier process going from legal knowledge to rhetoric logical structures and discursive strategies. What remains to be seen is if such an interactive course may be introduced in larger groups of students. (Marion Charret-Del Bove, Université Lyon 3)

\section{Introduction: the setting and the goals}

6 Teaching Legal English (LE) has a long tradition at the University of Niš, Serbia, where it is taught at the Faculty of Law at Bachelor's degree level an obligatory course in two terms at years one and four as an elective course at Master's level. LE courses consist of both lectures and classes, each three times per week, with up to ten students per group. The syllabus of Legal English course focuses on typical representative lexicogrammatical, rhetorical and stylistic features of legal discourse. Regarding the areas of legal practice the course corresponds to the overall structure of the study program, following it thematically, with topics on criminal law, criminal procedure ${ }^{1}$ opening and closing statements, and alike. One of the most relevant segments of the LE course syllabus is concerned with instructing students on the linguistic, rhetoric and discourse dynamics for achieving persuasiveness, that is the incorporation of Academic English formats and the academic genre of legal problem answer ${ }^{2}$. The learning outcomes are empowering students with professional linguistic skills that lawyers regularly apply (Nathanson 1997). Detailed example of the whole process of this instruction is given in the Appendix. Figure 1 illustrates three major stages in building up students' knowledge both in their domain and in English towards achieving persuasiveness. 
Fig. 1 Stages in the process of teaching persuasiveness in Legal English

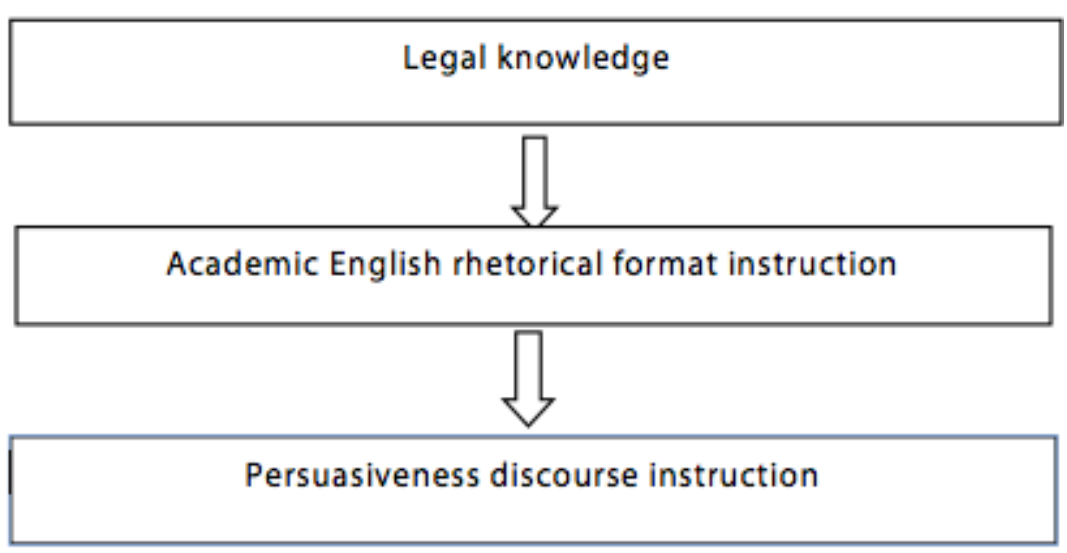

\section{Rhetoric practice design}

Based on extensive research into the rhetorical needs of future lawyers, the author presents a piece of practice work whose generic topic is achieving persuasiveness. Through this mostly rhetorical practice, the learning outcomes are for law students to master the inherent underlying logic of most professional situations they will find themselves in and to develop a sense of critical thinking. They should master rhetorical skills such as concession, contingency and end-focus, that serve to convert legal reasoning into balanced, effective and economical legal answer to a particular legal issue. Such are concession, contingency and end-focus, that serve to convert legal reasoning into balanced, effective and economical legal answer to a particular legal issue. Thus, the LE practice presented here is a much needed functional and applicative segment of legal education that is carried on in an ever increasingly globalized, internationalized and multicultural world, interdisciplinary in nature, aiming to prepare law professionals to freely use their legal expertise in cross-cultural legal contexts. For this reason, students of law nowadays need three kinds of knowledge: expert, legal, and linguistic, which in terms of LE syllabus implies an interdisciplinary approach to legal, content knowledge and legal domain specific linguistic skills.

8 There are three phases of instruction. The first one introduces legal knowledge needed as the content in which actual language instructions will be conducted. The next one deals with academic English. Academic English awareness and the mastery of it are the preconditions for dealing with Legal English formats, and so with persuasiveness as well. This phase begins with introducing students with the current linguistic understanding of text - identified as bearing closely similar underlying rhetorical logic either written or spoken. The Academic Legal English part focuses on clear, comprehensive articulation of argumentation. It begins with the basics, the principles of formulating title and paragraph topic sentence that contain the thesis, then proceeds to paragraph structure to incorporate all this into larger pieces of text.

Once these are completed, there is a transition to the legal genres of case reports (appeal court), statutes (ordinances), and problem question answers, treated cumulatively to show inherent generic rhetoric logical moves - advocacy, speculative argumentation, rebuttal, sustained analysis, as well as rhetorical functions of causation, 
condition, concession, permission, exemption, authorization, claims of foreseeability, obligation claims, and the corresponding linguistic structures, illustrating that "the structure is the most important aspect of a successful answer" (Gaskel 1995: 87).

\section{Questions as a major methodological approach}

10 The methodology applied is inductive in the first part of the lesson, the reason being the scarcity of time available during the course, but justified by the fact that students need only a short introduction into the logic of the studied rhetorical segment. Then, the central and the largest part of this instruction is based on a discussion guided by open questions asked by the lecturer inviting students to come up with answers, leading them to their own comprehending the scaffolding logic of the structure presented. There is also deduction and brainstorming. Therefore, instead of classical lecturing, the lecturer's introduction in the form of presenting the topic and the rationale for its application is followed by an extensive sequence of questions that lead students to provide answers during discussion in class by recognizing the direct link between the linguistic question and its professional setting, remembering examples from their experience. In this way, some of central teaching outcomes of the syllabus are achieved: critical thinking, relating domain knowledge to linguistic knowledge employed in professional settings, learners' autonomy.

\section{Introducing academic English}

Before commencing work on conceptualizing and achieving persuasiveness in legal settings, students need to be introduced to basic rhetorical structures of academic English since almost none of the students have previously had any dedicated instruction on rhetoric, its structures and actual use in real settings. This is needed for them to grasp the inherent logic of analytical discourse from which they will then build their case. Lecturer explains that this segment of instruction is present in all their professional communications, and will thus serve as the necessary foundation for proceeding to the crown skill of their discourse, which is persuading.

\section{An example of argumentative rhetoric instruction}

The work begins with the title of their speech or written piece that they are to produce at the end of this stage of instruction ${ }^{3}$. The lecturer asks them questions that guide them sequentially. First there are questions on the basis of which students are to understand the psychological relevance and impact of titles. Those are of the following type: "What does the title say? Why? Can it direct the audience in some/any way? If so, how? ..." Done as a brainstorming collective activity, this brings students to understand the title is of huge relevance for directing audience's attention towards the relevance of the case they are presenting. Once this is established, these insights are used to properly formulate an informative title.

13 The lecturer would, for example, ask what information the title "Intellectual Property" offers. As students find it too general and lacking in specificities, they would be asked to alter it in a concise way. 
14 At this stage students begin to struggle as they usually first come up with long variants, unaccustomed to expressing their thoughts in a clear, short, but potent manner. Therefore, we work together on eliminating unnecessary wordings and information, in an attempt to capture their main point, which may be for instance "Intellectual Property Breach".

15 And then again through a series of guided questions relating to the setting, the actual case, their stance, and alike, they would come up with complete titles that state the full case and their own position towards it, like "The Criminal Case of Intentional Intellectual Property Breach and the Conscious Design of its Concealing".

16 This phase would be rounded up by reiterating deductively what is achieved with such a title, namely showing that the case in question will be referred to as, and treated from the perspective of being a criminal act, that the argumentation will prove it is of premeditated nature that the court should condemn. Language issues are stressed, namely the reinforced use of synonyms - "intentional" and "conscious" which has the purpose of inducing in the minds of recipients the inclination advocated for - the condemnation of the act. This method is then applied to articulating the thesis, paragraphs, and finally the argumentative essay which is the central aim of the instruction on Academic English. The segments of such an essay are as described below:

17 - Introductory paragraph stating the thesis, the stance taken, along with an outline of the argumentation on which it rests.

18 - Body of essay comprising paragraphs each elaborating a single argument. For psychological impact it is best to start with the strongest, and continue the sequence with the remaining ones.

19 - Acknowledging possible/projected arguments of the opponent, but formulate those in such a way as to restrain their impact, by using wordings such as "Defendant/ Prosecution mistakenly contends/appear to argue that..."

20 - Rounding up by rephrasing the stance boldly using strong language to induce the agreement in your audience with the opinion you defend.

21 All this is needed as a comprehensive model for the layout of legal arguments into a coherent, impregnable net of arguments students are to know how to exhibit in criminal court during a criminal procedure, either as prosecution or defense, in order to outweigh the opposing side by constructing a winning version of the event (Bennett \& Feldman 1981).

\section{Steps in achieving persuasiveness}

\section{Identifying an arguable case and communicating it adequately}

22 In Legal English teaching, practitioners are very much aware that content and language instruction are so tightly interwoven that students sometimes cannot tell the two apart. One such instance is that while teaching legal rhetoric, students may occasionally have issues identifying a debatable from straightforward case, based on which the linguistic instruction is to follow. For this purpose students are presented with a description of a criminal act of the kind they had previously chosen as relevant in regards with their major, and are asked to identify key issues, material facts, which legal procedures are to be taken, to construe probable outcome, and identify 
contentious issues in the case. This phase should also be carried out through a chain of guided, open questions that will assist students to formulate their arguments, for example:

\section{on building persuasiveness starts by making a transition from content to} communicative focus, guiding students towards most effective and communicatively dynamic way of structuring their stance. First, there is the stating of their legal position. Students are here asked to remind themselves of the principles of title formulating and to employ the same logic in stating their position, and at the same time claim its supremacy over the possible, undisclosed arguments that may run against it. Students are told that this is called an open claim, since counter opinions/ facts/evidence are expected. The presented information needs to have a clear, precise and economical formulation of one's position regarding the issue in question. It is based only on facts and argumentative reasoning, that is on critical information, in order to justify the final decision towards which the argumentation is intended. It is crucially important to strip this presentation of any emotional or moral (moralizing) nuances as that significantly weakens the position regardless of how arguments may be feasible. All fact-based arguments presented in this opening segment are to be developed and fully elaborated further on. Arguments should be formed in such a way as to either outweigh confronting stance (e.g. court cases) or open the way for discussion and negotiation (e.g. mediation cases). Again, in relation to concrete situations, one more segment is mandatory and that is reflecting precisely in favor of (or against) whom/which the stance is taken. To take the example from the Academic English section for the sake of clarity of instruction process, students would in this part come up with the following formulation of the case and their argumentation stance: "Intentional Intellectual Property Theft of the X Company Hidden under the False Pretext of Working along Mutual Interests".

\subsection{Rhetorical structuring of argumentation flow}

The focus of all persuasive arguments is an objective analysis of the situation in question, gathering relevant facts and data, both favorable for the case and not. Persuasiveness begins when the given findings are considered not as fixed and constant, but malleable (Stanchi 2011). This is a common legal practice which both tells 
of the way law is interpreted and the rhetoric used for that purpose, law application and the rhetoric used being inseparable, one reflecting the other. Malleable as a qualification of law interpretation means there are different possible answers for the issue in question. Awareness of those variations is what allows for constructing the focal argument in favor of one's client or aim. In other words, organizing persuasive arguments implies the prediction of the outcome based on the facts and the available case law, and then working backwards from that awareness to construct the most persuasive analysis in support or opposition to the primary findings.

The overall strategy in persuasive argumentation is to present argumentation flow in the following way: the focal argument first and then select the others in terms of their strength for the case, elaborating each at a time. Anticipated or presented opponent's views are then to be accounted for and strongly refuted by reiterating the validity of the stance taken. The argumentation is finalized with an assertive conclusion that unequivocally and openly states the outcome argued for, by saying for example - the court should drop the case against this client because the charges do not bear substantial evidence as proved in my argumentation.

The argumentation begins with the central argument to highlight its overarching relevance. There is a psychological reasoning for this, as the audience will best respond if they are immediately confronted with an issue. The next step is the persuasive rule. Here the departure from firm Issue, Rule, Analysis, Conclusion (IRAC) format comes to the fore. The rule is an objective and neutral statement of the statutory rule, and a persuasive rule depends not just on legal interpretation in favor of the contested case, but equally so on the linguistic formulation and rhetorical performance that makes a compelling narrative, supported by facts and legal references, in which however, unfavorable facts are deemphasized.

What follows are further, smaller arguments prioritized according to their overall relevance as support to the main aim, strength of the law, judicial priority. Then it is advisable to sequence the rebuttal of the (anticipated) opposing main argument clearly indicating it stems from all argumentation previously exhibited. This flow of argumentation from the central argument, then supportive in order of their strength is the rhetorical maneuvering to outweigh the counter stance which is presented to demonstrate the awareness of its legal value and implications. Speaking in rhetorical terms, students need to learn to subordinate their arguments to the central argument, but also subordinate the counter evidence to the entire argumentation flow. Speaking in syntactic terms, the counter evidence should be put in the subordinate clause, and the main point in the main clause which is to end the sentence giving it thus a conclusive effect. The syntactic persuasive strategy is that if the conclusion is positive, meaning that the positive criterion is fulfilled and the negative dismissed, the author provides an elegant culmination of persuasiveness by ending with the positive information, and the opposite way around if the intended resolution is negative.

\subsection{Persuasive discourse}

Legal argumentation is a kind of narrative that builds up towards a desired climax. Communicating legal cases therefore is done with utmost care regarding achieving that goal. The relevance of proper wordings and phrases is illustrated by analyzing the impact of the model previously given - "Intentional Intellectual Property Theft of the X 
Company Hidden under the False Pretext of Working along Mutual Interests." Students are invited to first single out words with the strongest impact, like 'intentional', 'theft', 'hidden', 'false', 'pretext', and then to explain how these words influence the reception of the case and opinion formation of the audience. This is how students learn the potential of rhetorical and discursive devices that allow for emphasizing or deemphasizing certain needed points, thus directing the attention and legal focus towards the attempted finale.

Then, this work expands to sentence structure. The use of appropriate syntax, that is the ordering of facts/conclusions/opinions in a specific way within a sentence, can gain the intended impact. A simple scheme of it is the following: if the desired conclusion is negative, then the facts conceded with (counter argument) come first in the subordinate clause, and the aimed negative conclusion second in the main clause, in a sentence indicating contrast between what is acknowledged and yet what is the desired outcome overarching the counter stance. A formulaic version of this would be: Although Subject $A$ has met criteria $X$ and $Y$, still they do not meet criterion $Z$, and therefore their claim has to be refuted. Or, in cases where the favorable outcome is aimed for, the formula is: Although Subject A does not meet criterion X, they fulfill all the other needed criteria, and should thus be pardoned. This is the syntactic dynamics of end-focus where the subordinate clause contains the adversarial focus. Bruce (1988) introduced a "wave" metaphor for the consecutive arguments that strengthen one's advocating by the power of reinforcement, for "the way the message is moved forward" (Firbas 1971, 133), from known to newly presented information. This initial syntactic model is then further elaborated by inserting additional information into it and by making it more complex and dynamic, along with paying more attention to using more advanced wording and synonyms to avoid crude repetitions. These can be possible for more advanced alterations to the above given examples: if the advocated outcome is negative - Given the fact/despite the fact that criterion $X$ is met, there still remains the unresolved issue of criterion $Y$, that unless criterion $Z$ is fulfilled, Subject A cannot expect to realize their claim. This model changes in the following way if the attempt is to positively conclude the case for Subject A: Since criterion $X$ has not been achieved, but criterion $Y$ has, this adds crucial meaning to the overall situation, so that providing criterion $Z$ is successful, Subject A has most certainly proved right. Discourse dynamics shows that shifting the focus of the advocated argument influences its cognitive reception and is the major tool in providing the persuasive effect for it.

These syntactic structures should be considered only as basic models. In extended situations, that is authentic legal discourse, instead of straightforward concessions, there are circumstantial or contingent complications that arise during the course of legal action. However, such initial work on syntax in the service of persuasion is a starting practice and illustrative point from which work on larger, complex, real-life simulation work begins, yet is based on the principles introduced in that initial stage of instruction. This core syntax based discourse model nonetheless illustrates how legal reasoning principles and communication are inextricably combined.

Students need not be necessarily urged to apply more elaborate and complex sentence structures instead of more simplistic ones that can and should be left as their own choice, depending on their eloquence or stylistic expression of their personality. What matters is that they learn how to concede the counter argument, that the situation does not meet certain criteria, and present the most powerful favorable evidence to 
their advocated stance. Making students aware of the effect they can reach by applying solid rhetorical knowledge to their content knowledge, procedural patterns and reasoning foundations, is the ultimate goal of the linguistic instruction that deals with rhetoric. This is instruction that induces students how to realize the desired communicative effect to their professional targets. The language choice and application of rhetorical structures, syntax, wording, tone, pronunciation, all are conducive to the actual formulation of professional content.

Regarding syntax, there is also the issue of subject-verb unit that subtly indicates and directs focus of attention and justification. Making the desired goal subject of a sentence will attract attention, and placing the unfavorable facts simply elsewhere in a sentence, but not a subject, will deflect significance. An illustrative, provisional formula may be expressed as follows: Subject A did try to help, the fact unrecognized enough by the Prosecutor B... highlights the goal of presenting Subject A in a favorable light, and downplays the position of the counter party. There are various ways to attain this cognitive outcome, many of which depend on the choice of words if a different sentence structure is employed. So, this same structure can be used putting the central goal in the subordinate clause, yet manipulating the center of positive attention with the choice of words, for example: The prosecutor B alleges that A... makes subject A a potential victim and so this type of a sentence achieves the same effect. Basically, syntactic rules govern the semantics if the subject is placed either at the beginning or the end of a sentence, where it carries the highest persuasive charge, while mid sentence positions diminish it.

40 Students also need to be aware of the inherent suggestive meaning of active vs. passive voice. While strong active verbs are preferred as more assertive and more easily comprehensive, they are also strategically in place when the intention is to focus on the actor/fact. Passive well serves the purpose of evading admission of responsibility, yet caution is needed so as not to obliterate the counter facts, but simply to suggest their weaker overall relevance.

\section{Assessment}

41 An added value of this segment of Legal English instruction is that students find it motivational and inspiring because they associate it with the most prominent and most desirable job positions, which then drives them to behave proactively. Then, other generic skills smoothly come to the fore as students begin to exhibit high creativity as they present their final tasks either as oral presentations or written pieces (then read in class), in both cases most often as court defense. Because of that, assessment of this particular segment of LE syllabus is carried out in the form of obligatory presentations during the course. It is our constant experience with every generation of students that they prepare and perform those presentations with eagerness to show their skills and enjoyment in acting out their desired roles. Their task is to choose a case and their approach to it and lay it out in front of the class. Their choice varies, but is often inspired by actual events, those lately being related to environmental issues, for example a fine on residences that use wood or coal for heating. Students then take up a side either of prosecution or defense in a simulated court proceedings of a citizen who refused to pay and protested against the fine. Prosecution simulation would lay out arguments that the fine must necessarily be administered regardless of the low income 
of such residents, offering social care solutions, whereas the defense would deny effectiveness of those and insist on social measures that would essentially upgrade the overall economic status of such citizens and therefore absolve their client.

The first and the largest part of the assessment process is done through peer review as fellow students comment on the persuasive features employed and their actual effectiveness. After an open discussion in which both the presenters and the rest of the students take an active part, students who were following the presentation are given an assessment sheet to fill in. The questions and marks are in the five point Likert scale format. It is crucial that prior to giving students these final tasks for presentation, the lecturer sets the criterion regarding which aspects are relevant, through a conversation with students, so that students precisely know it in advance. The criterion is usually based on grading the realization of the following issues: relevance of the case; legal adequacy of the content and the stance; appropriateness of the segmentation of the case layout; effectiveness of arguments presented; choice of professional lexis; formulation of arguments; overall success/effectiveness of the presented material.

Finally, the lecturer gives the overall mark for this activity, which is then included in the cumulative final mark, and provides relevant comments and explanations that students can use to further improve. This mark is given according to the same criteria set for peer review and is elaborated to the students. The fact that the lecturer's mark most often complies with that of peers only proves the goal of this instruction has been achieved - students have internalized the principles of achieving persuasion in their legal activities and are able to effectively articulate them.

This report was drawn from a keynote address and workshop the author gave at "Share and Gain" workshops in LSP, University of Białystok, Poland, 7-8 September, 2018.

\section{BIBLIOGRAPHY}

BENNETT, W. L. \& M. S. FELDMAN. 1981. Reconstructing Reality in the Courtroom. London: Tavistock Publications.

BRUCE, N. 1988. "Communicative dynamism in expository academic English: Some strategies in teaching the pragmatics of writing". Working Papers in Linguistics and Language Teaching 11, 42-53. FIRBAS, J. 1971. "On the concept of communicative dynamism in the theory of functional sentence perspective”. Universitas Brunensis, Studia Minora A19, 135-144.

GASKELL, N. 1995. “Answering law exam problems and essays”. In Krever, R. E. (ed.), Mastering Law Studies and Law Exam Techniques. Sydney: Butterworths, 78-85.

NATHANSON, S. 1997. What Lawyers Do: A problem-solving approach to legal practice. London: Sweet and Maxwell.

STANCHI, K. 2011. "Teaching first semester students that objectiveness is persuasive". Journal of the Legal Writing Institute, 167-177. 


\section{APPENDIXES}

\section{Appendix: Major steps in practicing persuasiveness}

\begin{tabular}{|c|c|}
\hline \multicolumn{2}{|c|}{ Checking professional knowledge domain expert knowledge } \\
\hline LECTURERS & STUDENTS \\
\hline $\begin{array}{l}\text { Present students with a case, do reading } \\
\text { comprehension, ask open questions about the case, } \\
\text { drive students towards determining whether that is } \\
\text { an arguable case. }\end{array}$ & $\begin{array}{l}\text { Read for understanding, answer lecturer's } \\
\text { questions, activate their own knowledge } \\
\text { and decide whether the case presented can } \\
\text { be a trial case. }\end{array}$ \\
\hline $\begin{array}{l}\text { Case analysis in terms of domain knowledge, } \\
\text { questions relating to the type of offence/crime, } \\
\text { probable cause, motives. }\end{array}$ & $\begin{array}{l}\text { Group work simulating team work in a } \\
\text { professional environment, brainstorming to } \\
\text { answer lecturer's questions. }\end{array}$ \\
\hline $\begin{array}{l}\text { Final stage of expert knowledge discussion - } \\
\text { challenging for weak points. }\end{array}$ & $\begin{array}{l}\text { Students work in groups or pairs taking } \\
\text { opposing stances, one group presents one } \\
\text { while the other challenges their views. }\end{array}$ \\
\hline \multicolumn{2}{|c|}{$\begin{array}{l}\text { Formulating most feasible approach to win the case in court (domain knowledge and its linguistic } \\
\text { and rhetorical formulation) }\end{array}$} \\
\hline Instructing students in facts abstraction. & $\begin{array}{l}\text { Students abstract the core segments of the } \\
\text { case and practise its summary presentation } \\
\text { to the rest of the team. }\end{array}$ \\
\hline $\begin{array}{l}\text { Have students choose the court role - prosecution or } \\
\text { defense. }\end{array}$ & $\begin{array}{l}\text { Decide which role they wish to enact, } \\
\text { explicate their reasons. }\end{array}$ \\
\hline \multicolumn{2}{|l|}{ Lecture on Academic English rhetoric formats } \\
\hline $\begin{array}{l}\text { Asks for the major arguments they believe could } \\
\text { sustain their stance. }\end{array}$ & $\begin{array}{l}\text { Students are asked to employ principles of } \\
\text { Academic English argumentation } \\
\text { instruction and formulate their major } \\
\text { arguments. }\end{array}$ \\
\hline $\begin{array}{l}\text { Invites students to decide on the arguments } \\
\text { sequence. }\end{array}$ & $\begin{array}{l}\text { Based on their Academic English knowledge } \\
\text { they devise the argumentation flow. }\end{array}$ \\
\hline \multicolumn{2}{|l|}{ Simulation of the court presentation } \\
\hline $\begin{array}{l}\text { Gives tasks to prepare prosecution/defense on the } \\
\text { given case based on the Academic English } \\
\text { instruction on rhetorical structure of argumentative } \\
\text { thesis/title/paragraph/essay. }\end{array}$ & $\begin{array}{l}\text { In groups (simulating teams) students } \\
\text { prepare their argumentation presentation. }\end{array}$ \\
\hline $\begin{array}{l}\text { Provides hints as to body posture, voice strength and } \\
\text { articulation, eye contact. }\end{array}$ & $\begin{array}{l}\text { One student in front of the group/team } \\
\text { gives his/her presentation. }\end{array}$ \\
\hline
\end{tabular}




\begin{tabular}{|l|l|}
\hline $\begin{array}{l}\text { Asks students to discuss the performances both from } \\
\text { content and linguistic view point - whether } \\
\text { persuasiveness was achieved and with which means. }\end{array}$ & $\begin{array}{l}\text { All students engage in free, open discussion } \\
\text { about their impressions of the performance. }\end{array}$ \\
\hline Evaluation & $\begin{array}{l}\text { Students evaluate presentations in the } \\
\text { following aspects: professional knowledge, } \\
\text { appropriate linguistic knowledge, behavior. }\end{array}$ \\
\hline Prepares students for peer evaluation. & \\
\hline Presents his or her evaluation & \\
\hline $\begin{array}{l}\text { Finalize the mark for students' practice work on } \\
\text { persuasiveness. }\end{array}$ & \\
\hline
\end{tabular}

\section{NOTES}

1. Stages, legal standards, Inquisitorial and Adversarial legal system, pre-trial proceedings, police proceedings, prosecution and indictment, preliminary court proceeding, jury selection, criminal trial; legal skills of trial advocacy, admissible and inadmissible questions in court; lawyer skills .

2. Problem answer is a concept underlying most of legal practices and refers to legally solving the given situation.

3. This instruction is finalized with students presenting their own pieces either orally or in a written format, depending on which type of legal situation they chose, in both cases it most often is a court defence. If an oral presentation, it is to fit within a five minute frame and is followed by discussion in which all students take part by asking the presenter questions relating to the legal content and also the structure and wording of it. If it is a written piece it is in the form of a particular legal document of student's choice, most often defence notes. The length should not exceed a single A4 page, of 12 font size, single spaced. In either case, students' work needs to comply with the academic English principles of building argumentation and anticipating and outweighing counter argumentation.

\section{INDEX}

Keywords: legal English, persuasiveness, teaching course

Mots-clés: anglais du droit, cours de langue, persuasion 
AUTHOR

NADEŽDA STOJKOVIĆ

Associate Professor, University of Niš, Serbia, Nadezda.Stojkovic@elfak.ni.ac.rs 